\title{
On Productivity and Technology Diffusion in Nigeria
}

\author{
Ndem Ayara Ndiyo \\ Department of Economics, University of Calabar, Nigeria
}

\section{ABSTRACT}

This study analyses the long-term trend in knowledge diffusion and productivity growth in Nigeria using a translog specification. The results indicate the need for technological upgrading and imply that policies designed to promote technological development should address the complementarities between different factors of production. The article, thus, provides some support for the argument that total factor productivity (TFP) is technological knowledge and can impact significantly on productivity in a developing economy.

JEL O14, O31, O32

\section{INTRODUCTION}

Technology is the bedrock of human civilization. It determines how production can be realized and sets limits on the amount and types of wealth that can be derived from a given combination of resources. The ultimate impact of technology is the enhancement of the well-being and influence of man through the creation of wealth. Technology achieves this impact by making man more productive in his environment (Adiele, 2002: 3-4). In the process, man gains a better understanding of his environment and enjoys a higher standard-of-living and control. In the world today, the nations that have acquired advanced technologies are also the most affluent and most powerful nations.

Economic literature suggests that technological deficiency is a critical factor in the analysis of productivity and of course the economic backwardness of developing economies. The quest for technological development is justified in terms of the hypothesis that a fast rate of economic growth is invariably related to high growth rate of inputs, of which technological development is an important aspect. This is perhaps because economic growth, technical change and productivity are closely linked. Change in technology is a critical factor, which enables man to utilize his resource environment more efficiently and to generate the increases in productivity, which are at the heart of the process of 
economic growth. Therefore, output may be increased by technological innovations, which increase the productivity of the existing supply of resources.

The characteristics of technology as an economic good may explain why this initially neglected and now widely investigated factor of production remains relatively concealed. Technology (which is a method of doing things) is a public good with property rights that are rarely enforceable (Navaretti \& Tarr, 2000: 2). It is hardly quantified or priced; it is sometimes codified, but more frequently tacit and difficult to observe. Although well established in economic theory, the link between technology and productivity has been tested by relatively few rigorous empirical studies. The international reference often quoted in this area is Coe and Helpman (1995), which focuses on knowledge diffusion among Organizations for Economic Co-operation and Development (OECD) countries. Such aggregative studies assume uniformity in factors of production across countries, which may not necessarily be the case. In Nigeria specifically, previous attempts are usually based on the Cobb-Douglas specification of the production function, which assumes unitary elasticity of substitution between labour and capital, and Hicks-neutrality of technical progress. However, an empirical estimation of the technology function using the Translog production function has not been attempted so far. Typically, if technology is upgraded production processes are enhanced. However, the link between technology and productivity is often assumed to be exogenously determined in the production process.

This study is motivated by the need for a deeper understanding of the impact of technological diffusion on productivity performance in Nigeria. An empirical analysis of the links between productivity and knowledge diffusion is useful for distilling out some of the key predictions of the theory of endogenous growth models. The focus of this article is, therefore, devoted to the empirical analysis of the diffusion of technological knowledge and economic performance in Nigeria. The study attempts to measure the relative contribution to economic growth resulting from technological knowledge and raising productivity of resources. The above objective is achieved by, first of all discussing the relationship between technological knowledge and productivity after examining some conceptual issues in Section 2. This is followed by the framework of analysis and some methodological arguments in Section 3. The empirical results and research outcomes are presented in Section 4 of the paper. Implications and concluding remarks close the study in Sections 5 and 6. 


\section{CONCEPTUAL ISSUES}

Productivity is a quantitative relationship between output and inputs (Iyaniwura \& Osoba, 1983; Antle \& Capalbo, 1988, Oyeranti, 2000). As long as the basic concept refers to the relationship between the quantity/quality of goods and services produced, this definition of productivity remains the same regardless of the type of production system. In other words, productivity is a ratio of some measure of output to some index of inputs used or the ratio between the quantity of resources used in the course of production. This concept of productivity implies the efficiency with which resources are utilized in production. In effect, productivity becomes an index for measuring the attainment of the highest level of performance with the lowest possible expenditure of resources (Eatwell \& Newman, 1991; Samuelson \& Nordhaus, 1995; Prokopenko, 1987).

However, productivity is measured by how efficiently resources are transformed from inputs to output, which can also be measured in relation to each of the factors of production. A distinction is made between productivity of labour, productivity of capital, productivity of land and productivity of the entrepreneur. This makes productivity an encapsulating concept that is comprehensively distinctive. Thus, the conditions that lead to the improvement of productivity of any factor would vary according to which resource is under consideration. The differential becomes even more pronounced when we consider intersectoral and interindustry characteristics, which are seldom uniform. Basically, productivity provides the basis for analyzing the relative dynamism of different economic activities. The increasing focus on productivity is directed towards being able to know more about the process of technical change.

It is common practice to classify inputs into land (gifts of nature), labour (human resources), capital (physical and financial assets), and material. Olaoye (1985) argues that productivity as a concept has two dimensions: namely, partial factor productivity (PFP) and total factor productivity (TFP). PFP relates output to any factor input, implying that there will be as many measures of productivity as inputs involved in the production process. PFP relates to labour productivity, capital productivity, land productivity, etc. This average product concept measures only output per unit input, ignoring the contributions of other factors to the detriment of production process reality. On the other hand, TFP measures the relationship between output and a composite index of inputs (i.e., the sum of basic resources notably labour, capital goods and natural resources). At the moment, research interest on productivity has focused more on PFP measures, in which comprehensive aggregates of outputs and inputs are related.

However, it is common in productivity literature to see emphasis being placed on labour productivity. One justification for the special emphasis on labour 
productivity is perhaps the fact that labour is a universal key resource (Oyeranti, 2000). However, in recent times, advancement in information technology seems to suggest that labour productivity may actually be subordinate to the productivity of capital and other scarce resources such as energy or raw materials. Therefore, productivity is better perceived as the end result of a complex social process involving science, research, training, technology, management, production plant, trade union, as well as labour among other interrelated factors. It is a comprehensive measure that is concerned with efficiency and effectiveness simultaneously.

The quest for technological development, the world over, is to ensure continued improvement in the standard of living of the people. The ability of a country to sustain rapid economic growth in the long run is highly dependent on the effectiveness with which its institutions and policies support the technological transformation and innovativeness of its enterprises. This perhaps emanates from the close link between technology and education, knowledge and skills. Technological progress entails improved ways and methods of doing things. Skills, know-how and advancement in knowledge encapsulate technological growth. The improvements in knowledge and know-how are also propagated through education, training and research. It is now obvious that to be a part of the world, there must be science and technology elements in the development process. Expanding access to science and technology information and capacity into developing regions will similarly accelerate the paths to development and prosperity in an environmentally sustainable manner.

The three main stages of technological development are invention, innovation and diffusion (or adaptation) of invention. The invention stage involves the articulation of ideas, which will eventually help to improve existing methods of doing things. Innovation as the second stage is concerned with the process by which inventions are systematically harnessed into new techniques or products, while the third stage, diffusion of invention, consist of commercial production and widespread use of new techniques or new products among potential alternatives (Inang, 1982: 34). It should be stressed at this point that, although the diffusion of existing technology is emphasized in this review, continued and sustained growth requires the persistent search for and the introduction of improved methods that are embodied in the former two stages.

Technological development has over the years been pioneered largely by the advanced industrialized countries which are able to mobilize the huge financial and other resources usually needed for achieving technological progress. The pursuit of technological development in Nigeria has been generally approximated with the desire for rapid industrial development. In the less developed countries (LDCs), technological progress has been very slow, and, 
sometime, almost non-existing, because of the dearth of capital coupled with weak existing national capacities, and sometimes outright unwillingness on the part of the industrialized countries to part with technological knows-how (Inang, 1982: 314-515).

However, the basic motives for wanting technological development are enormous. Advances in agricultural biotechnology will be essential for raising developing world food productivity in order to feed burgeoning populations. New technology applications will be crucial to providing adequate and safe water supplies. Clean and renewable energy technologies will be needed to ensure sufficient and sustainable energy supplies for the developing world. Similarly, advances in biomedical science and technologies are critical if developing countries are to overcome the daunting public health challenges posed by infectious diseases. However, some advances, such as wireless communications and fuel cells for transportation or distribution of power, can leapfrog older technologies. The above is just a small sampling of areas in which science and technology advances can have enormous beneficial leverage.

\subsection{Technology and production}

Technology is holistic to production because production says "what" is produced while technology demonstrates "how" it is produced. In fact, production and technology may mean the same thing and are often use interchangeably in reference to the process of wealth creation (Adiele, 2002: 8). The essence of production is to create new utility, with the aid of technology. However, a given technology remains unchanged in a particular production process regardless of how long the production process continues. Hence, technology is a catalyst in the production process. Technology is fast changing the global economic landscape by increasing the importance of knowledge as a factor of production. It is also changing the nature of markets, competition, and source of comparative advantage. Fueled by research and the rapid generation of new techniques, technological innovation has become the major factor behind increases in productivity. Lucas (1988), Young (1991) and Stokey (1988; 1991) attribute productivity growth to learning processes, which facilitate the production of increasingly sophisticated products and the accompanying knowledge spillovers. In this way, the more rapidly learning takes place, through schooling or through learning by doing, the higher is the rate at which new high-tech products are introduced into the market, and the higher is the rate of productivity growth.

However, in models of economic growth (whether neoclassical or evolutionary), technology usually gets reduced to a single number: total factor productivity (TFP). As a source of TFP, technology combines with capital, land, and labour 
to produce goods and services. One effect of technological change is to alter the nature of goods, markets, and competition of firms. The great speed of technological change and the rapid accumulation of new techniques demonstrate that firms failing to incorporate new technological knowledge in their production processes lag behind in productivity and competitiveness.

Technology is a practical description or a demonstration of the entire production process (Adiele, 2002: 3). Output depends on many factors (inputs) including the total hours of labour, education of the workforce, technology and the amount of capital. Output growth, in turn, depends on changes in these factors. In particular, the contribution of technology to output growth is the amount by which output growth would have been reduced if the stock of knowledge capital had not changed while all the other factors that affect output changed. The size of this contribution depends on the importance of the level of technology relative to other factors. It is widely accepted that production theory remains the basis for analyzing the factors that explain changes in output levels resulting from three basic factors; namely, (i) the quality and quality of resources utilised in the production process; (ii) the state of technology or kind of production process that is in use; and (iii) the efficiency with which resources are utilized (Oyeranti, 2000: 13-14). These factors measure the differences in productive efficiency, the scale of production, and the state of production technology employed. In this way technology is gradually gaining prominence in the production function. The section, which follows this one, formalizes this intuition and then uses the framework to analyze the contribution of technology to output growth in Nigeria.

\section{FRAMEWORK FOR ANALYSIS}

The framework used to assess the role of technology in productivity growth is the standard growth accounting framework. Growth accounting allocates the growth rate of national output among the determinants of output that changed and caused growth. It has, however, been demonstrated that the production function methodology can underestimate or ignore the use of improved technologies at the firm level, thereby affecting estimates of Multi-Factor Productivity (MFP) growth (Nelson \& Pack, 1998; Djankov \& Hoekman, 2000). Moreover, differences in technological capacity across firms in an industry may be an important determinant of MFP. Data confirming these differences is hard to come by, as information on variables relevant to the level of technology of individual firms and the composition of their workforces is hardly available.

The trends in the practical productivity indices with respect to individual factors, include the effect of capital depending on the context of capital accumulation in 
a growing economy. Thus, increases in labour productivity may be due to improved efficiency and technological progress as well as the employment of more capital per unit of labour. However, the latter two sets of influences do not operate independently of each other. More specifically, labour productivity may increase because of improved and larger numbers of machines. In fact, if capital investment generates positive externalities, then investment in capital generates social returns in excess of the private returns to firms that made the investment. Romer (1990) argues that capital accumulation may result in knowledge spillovers, where increases in the level of capital stock not only increase the productive resources of the firm, but also increase the level of technology available to other firms.

The production relationship can be formally derived by assuming that the aggregate production function takes the simple form:

Where

$$
\mathrm{Y}=\mathrm{f}\left(\mathrm{L}^{\alpha}, \mathrm{K}^{\beta}, \mathrm{e}^{\lambda t}\right)
$$

$$
\begin{aligned}
& \mathrm{Y}=\text { Output } \\
& \mathrm{K}=\quad \text { Capital input } \\
& \mathrm{L}=\text { Labour input } \\
& \lambda \mathrm{t} \text { represents a measure of technological diffusion in production over } \\
& \text { time. }
\end{aligned}
$$

The production function in equation (1) implies the following relation between marginal physical products (MPPs) and output:

$$
\mathrm{Y}^{\prime}=\alpha f^{\prime}(\mathrm{L})+\beta f^{\prime} \mathrm{K}+\lambda \mathrm{t}
$$

In equation (2) $\lambda t$ measures the technology change or total factor productivity (TFP) growth which may not be accounted for by the increase in inputs used. This implies that beyond partial factor productivity, the growth of output can be decomposed into the contribution of changes in inputs and in TFP. Thus, the production function relates the contribution of additional inputs to changes in output and the residual, otherwise called 'multi-factor productivity growth' MFPG. The observed increase in $\lambda t$ will underscore the impact of pure productivity of capital and labour in production. It is reasonable, therefore, to argue that in a situation where capital intensity is increasing over time, the analysis of partial productivity changes would overstate the increase in labour productivity and understate the increase in capital productivity.

Two approaches are used in the measurement of TFP; namely (i) the growth accounting approach, and (ii) econometric approach (Antle \& Capalbo, 1988; Oyeranti, 2000). The growth accounting methodology involves compiling detailed accounts of inputs and outputs, summing them into input and output 
indices, and using the indices to calculate a TFP index. The origins of the growth accounting framework and multifactor productivity (MFP) growth theories can be traced to Tinbergen (1942) and Solow (1957). The literature on the subject has continued to grow subsequently, reflecting advances in the theory of production and the theory of index numbers and aggregation. The econometric approach on the other hand, involves the specification of a function representing technology as a production function and estimating the derivatives.

Thus, differentiating the production function with respect to time yields:

$\mathrm{Y}=\mathrm{s}_{\mathrm{L}} \mathrm{L}+\mathrm{s}_{\mathrm{K}} \mathrm{K}+\mathrm{MFP}$

Where $\mathrm{L}^{\prime}, \mathrm{K}^{\prime}$ and MFP represent the growth rates of the labour input, real capital stock, and multi-factor productivity, respectively, and $\mathrm{s}_{\mathrm{L}}$ and $\mathrm{s}_{\mathrm{K}}$ are the income shares of the labour input and the capital stock. Under the assumption of competitive equilibrium suggesting that factors of production are paid the value of their respective marginal products and constant returns to scale, the rate of growth of output can be written as:

$$
\begin{array}{rll}
\text { Wy } & =\mathrm{s}_{\mathrm{L}} \mathrm{g}_{\mathrm{L}}+\left(1-\mathrm{s}_{\mathrm{L}}\right) \mathrm{g}_{\mathrm{K}}+\lambda \\
\text { gy } & = & \text { the growth rate of output } \\
\mathrm{g}_{\mathrm{L}} & = & \text { the growth rate of labour } \\
\mathrm{g}_{\mathrm{k}} & = & \text { the growth rate of capital } \\
\mathrm{S}_{\mathrm{L}} & = & \text { the share of labour in output } \\
1-\mathrm{S}_{\mathrm{L}} & = & \text { the share of capital in output } \\
\lambda & = & \text { residual }
\end{array}
$$

Under the specific assumptions that are made with respect to the production function and market conditions, $\lambda$ measures that part of growth that cannot be explained by either growth of labour or capital. $\lambda$ is technically the growth of the weighted sum of all inputs.

By relying on MFP as the dependent variable, we assume that the adoption of new technologies will, with some lag, improve productivity. One problem with this assumption is that as the case-study literature has documented, such improvements depend on the absorptive capacity of domestic firms (Djankov \& Hoekman, 2000). The Solow concept of MFP growth is unambiguous for infinitesimally small shifts in technology in continuous time. Empirical estimates of productivity change, however, are based on a discrete set of price and quantity data. A solution to this problem lies in using a "flexible" functional form of production function, which is a second-order approximation to any arbitrary production function, which is twice differentiable. One such 
flexible functional form is the logarithmic (Translog) production function developed by Christensen, et al. $(1971,1973)$ and popularized by Ahluwalia (1991). It does not only naturally accommodate discrete time analysis, but also imposes fewer a priori restrictions on the underlying technology of production, and may not assume a Hicks-neutral or a constant rate of technology change. The function is written as:

$\log \mathrm{Y}=\alpha_{0}+\alpha_{\mathrm{L}}(\log \mathrm{L})+\alpha_{\mathrm{k}}(\log \mathrm{K})+\alpha_{\mathrm{t}} \mathrm{t}+1 / 2 \beta_{\mathrm{LL}}(\log \mathrm{L})^{2}+1 / 2 \beta_{\mathrm{KK}}(\log$ $\mathrm{K})^{2}+\beta_{\mathrm{LK}}(\log \mathrm{L})(\log \mathrm{K})+\beta_{\mathrm{Lt}}(\log \mathrm{L}) \mathrm{t}+\beta_{\mathrm{kt}}(\log \mathrm{K}) \mathrm{t}+1 / 2 \beta_{\mathrm{tt}} t^{2}$

Where, the $\alpha$ s and $\beta$ s are the parameters of the production function.

Differentiating $\log Y$ with respect to $L$ and $K$, respectively, results in

$$
\begin{aligned}
& \frac{\partial \log Y}{\partial \mathrm{L}}=\alpha_{\mathrm{L}}+\beta_{\mathrm{LL}}(\log \mathrm{L})+\beta_{\mathrm{LK}}(\log \mathrm{K})+\beta_{\mathrm{Lt}} \mathrm{t} \\
& \frac{\partial \log \mathrm{Y}}{\partial \mathrm{K}}=\alpha_{\mathrm{K}}+\beta_{\mathrm{KK}}(\log \mathrm{K})+\beta_{\mathrm{LK}}(\log \mathrm{L})+\beta_{\mathrm{kt}} \mathrm{t}
\end{aligned}
$$

In this specification, the elasticity of output with respect to inputs is not constant but depends on input levels and time. This is in contrast with the Cobb-Douglas production function where these elasticities are constant. The coefficient of the Translog production function also provides information on the possibility of factor substitution within the model. When a coefficient is positive, under competitive equilibrium, the factor share increases with the level of the input, assuming the levels of other inputs remain unchanged. The rate of technical progress or total factor productivity growth in a Translog production function is given by:

$$
\frac{\partial \log Y}{\partial \mathrm{t}}=\alpha_{\mathrm{t}}+\beta_{\mathrm{tt}} \mathrm{t}+\beta_{\mathrm{Lt}}(\log \mathrm{L})+\beta_{\mathrm{kt}}(\log \mathrm{K})
$$

where $\alpha_{t}$ is the rate of autonomous TFP growth, $\beta_{\mathrm{tt}}$ is the rate of change of TFP growth, and $\beta_{\mathrm{Lt}}$ is positive, meaning that the share of capital increases with time and there is a capital-using bias. Following Ahluwalia (1991), the Translog estimate of TFPG can be written as:

$$
\begin{aligned}
& \left.\Delta \log \operatorname{TFP}_{(t)}\right)=\Delta \log \left(_{\mathrm{t}}\right)-1 / 2\left[\mathrm{~S}_{\mathrm{L}}(\mathrm{t})+\mathrm{S}_{\mathrm{L}}(\mathrm{t}-1)\right] \Delta \log \mathrm{L}(\mathrm{t})-1 / 2\left\{\left[1-\mathrm{S}_{\mathrm{L}}(\mathrm{t})\right]+\right. \\
& \left.\left[1-\mathrm{S}_{\mathrm{L}}(\mathrm{t}-1)\right]\right\} \Delta \log \mathrm{K}(\mathrm{t})
\end{aligned}
$$

Since the main focus of this article is to relate productivity growth and technology diffusion, equation (5) has been augmented by including capacity utilization (CU), the incremental capital-output ratio (ICOR) as well as the capital-labour $(\mathrm{K} / \mathrm{L})$ ratio as additional factors of production. Control variables 
for the effects of other changes in the economic environment are also required. Good proxies for these changes are not available nor can we account for each of them individually. For this reason an annual dummy variable $(\mathrm{T})$ is included in the estimation equation. This variable picks up the net effect of changes in the aggregate economy.

\subsection{Methodological arguments}

Data on the macro aspects of the Nigerian economy are all gathered from the CBN Statistical Bulletin and Statement of Accounts. The latest revised national accounts for 1998 and 2001 form the main sources of data for this analysis. As is well known, there is no universally accepted method of measuring capital stock because of the wide differences existing in the actual methodology used to build the estimates of capital stock. For this reason, gross fixed capital formation (including depreciation) as published by the CBN is used for this study. Since this resolution by its very nature is in the realm of second best, the results need to be viewed with appropriate caution.

The data analysis started with the ordinary least squares (OLS) method. But as usual, a common observation of the time series regressions reveals that the residuals are correlated with their own lagged values. This serial correlation violates the standard assumption of regression theory that disturbances are not correlated with other disturbances. Thus, standard errors computed using the textbook OLS technique are not correct and they are generally understated, biased and inconsistent. Because of the probable correlation between the productivity index and the independent variables, OLS may give biased and inconsistent estimates. This simultaneity problem is endemic to the empirical literature on measuring productivity.

One widely used model of serial correlation is the first-order autoregressive or AR(1) model. This study employs the AR models, using both linear and loglinear regression techniques. This approach has the advantage of being easy to understand, generally applicable and easily extended to non-linear specifications and models that contain endogenous right-hand variables. It should be noted that the estimates are asymptotically efficient. The approach also enhances the efficiency gain from the serial correlation correction. The coefficients may be interpreted in the usual manner, but the results involving the residuals, however differ from those computed in OLS settings. For the simple AR(1) model, the estimated parameter is the serial correlation coefficient of the unconditional residuals. Normally, there is no strong reason to examine these residuals.

For a stationary AR(1) model, the true marginal significance level lies between negative 1 (extreme negative serial correlation) and positive 1 (extreme positive 
serial correlation). The stationarity condition for general AR(1) processes is that the inverted roots of the lag polynomial lie inside the unit circle.

\section{RESEARCH OUTCOMES}

In order to examine the actual impact of factors of production on productivity, we have estimated factor-specific productivity functions, for which data are available. Estimates are carried out with semi-log and double-log formulations using the least squares technique. Although a large number of variables were included in the preliminary analysis, only a few of them find a place in the final analysis. In order to eliminate the less important variables and avoid a severe problem of multicolinearity, the correlation matrix ${ }^{1}$ approach has been used.

The variables for incorporation in the final specifications have been selected based on the correlation matrices. A number of permutations and combinations of the selected variables have been tried in order to select the good fit in terms of explanatory power and significance of the variables for the final analysis. After trying a number of variables, the final equations for interpretation as shown in Tables 1 and 2 below have been selected.

All through the presentation of the estimated results, the t-statistic for each coefficient appears in parenthesis below the coefficient. The term 'statistical significance' is used to indicate that the coefficient is significantly different from zero and is of the sign indicated at the conventional 5 per cent level of significance for a two-tailed test. In cases where the Durbin-Watson test rejects the hypothesis of zero autocorrelation, the equation is re-estimated correcting for the first-order autocorrelation using the AR(1).

Table 1 Time series estimate of restricted translog specification of productivity functions in Nigeria 1970-2000

\begin{tabular}{||c|c|c|c|c||}
\hline $\begin{array}{c}\text { Dependent } \\
\text { Variable/ } \\
\text { Independent } \\
\text { Variables }\end{array}$ & $\frac{\text { GDP }}{\text { LAB }}$ & $\begin{array}{c}\text { Log GDP } \\
\text { LAB }\end{array}$ & $\underline{\text { GDP }}$ & $\begin{array}{r}\text { Log GDP } \\
\text { GFCF }\end{array}$ \\
\hline Intercept & $3240.822 * * *$ & $9.968752^{* * *}$ & $21694.20 *$ & $9.952755^{* * *}$ \\
& $(3.46)$ & $(15.53)$ & $(1.92)$ & $(16.16)$ \\
\hline Lab & $-42.51723^{* *}$ & & $1365.202 * * *$ & \\
& $(-2.50)$ & & $(5.79)$ & \\
\hline GFCF & 2.847326 & & $-80.73023 * *$ & \\
& $(0.86)$ & & $(-2.06)$ & \\
\hline
\end{tabular}


Table 1 continued

\begin{tabular}{|c|c|c|c|c|}
\hline $\begin{array}{c}\text { Dependent } \\
\text { Variable/ } \\
\text { Independent } \\
\text { Variables }\end{array}$ & $\begin{array}{l}\text { GDP } \\
\text { LAB }\end{array}$ & $\log \frac{\text { GDP }}{\text { LAB }}$ & $\frac{\text { GDP }}{\text { GFCF }}$ & $\log \frac{\text { GDP }}{\text { GFCF }}$ \\
\hline Time & & $\begin{array}{c}0.002057 \\
(0.14)\end{array}$ & $\begin{array}{c}-3057.87 * * * \\
(-12.33)\end{array}$ & \\
\hline LogLab & & $\begin{array}{c}-0.85608 * * * \\
(-4.27)\end{array}$ & & $\begin{array}{c}0.157945 \\
(0.97)\end{array}$ \\
\hline LogGFCF & & $\begin{array}{c}0.155465^{* * * *} \\
(3.03)\end{array}$ & & $\begin{array}{c}-0.83802 * * * \\
(-28.76)\end{array}$ \\
\hline GFCF/LAB & & $\begin{array}{c}-0.017478^{*} \\
(-1.47) \\
\end{array}$ & & $\begin{array}{c}-0.018376^{*} \\
(-1.75)\end{array}$ \\
\hline $\mathrm{CU}$ & $\begin{array}{c}15.64316^{* *} \\
(2.06)\end{array}$ & $\begin{array}{c}0.007929^{* *} \\
(2.32)\end{array}$ & $\begin{array}{c}-333.922 * * * \\
(-3.53)\end{array}$ & $\begin{array}{c}0.007550 * * * \\
(4.41)\end{array}$ \\
\hline $\operatorname{AR}(1)$ & $\begin{array}{c}0.758040 * * * \\
(6.99)\end{array}$ & $\begin{array}{c}0.273865^{*} \\
(1.21)\end{array}$ & & $\begin{array}{c}0.279773^{*} \\
(1.44)\end{array}$ \\
\hline $\mathrm{R}^{2}$ & 0.85 & 0.92 & 0.93 & 0.99 \\
\hline Adj. $R^{2}$ & 0.82 & 0.89 & 0.92 & 0.99 \\
\hline DW & 2.05 & 1.91 & 1.37 & 1.91 \\
\hline RSS & 199.86 & 0.0896 & $2.60 \mathrm{E}+08$ & 0.0897 \\
\hline F-Stat & 26.56 & 41.06 & 67.48 & 3674.66 \\
\hline No of Observations & 31 & 30 & 31 & 30 \\
\hline
\end{tabular}

Note: (a) figures in parentheses are t-values;

(b) $*, * *$, and $* * *$ indicate increasing levels of significance at 10,5 , and 1 percent respectively.

Source: Author's calculations

The results on Table 1 indicate that the double-log specifications are better in terms of their explanatory power and level of significance. As expected a positive relationship was found between labour productivity and capital, as well as between capital productivity and labour. But in contrast to the a priori expectation, labour input contributed negatively to labour productivity while capital input impacted negatively on capital productivity. As found in earlier studies of productivity in Nigeria, these results also show that there are some depressing truths when estimating Nigeria's production function. As argued in Ndiyo (2002), the aggregate data used on the standard growth-accounting model suggest that education has not had the expected positive growth impact on economic growth in Nigeria that is so widely acknowledged by many. The resolution of this puzzle begins with a proper understanding of the causes of such an unanticipated relationship. Pritchett (2001) in a similar study observes that a single answer to this puzzle is grossly insufficient. It is theoretically quite possible that there could be a wasteful oversupply of education in today's 
developing economies. One of the best-known manifestations of this occurrence has come be called the external brain drain. This would certainly encourage brain drain since in an open economy like Nigeria, this will cause well-educated Nigerians to travel abroad for greener pastures. Clearly the brain drain is not the result of a simple quantitative oversupply of trained people. It comes about because too many are supplied with the kind of skills for which there is an insufficiency of effective demand at home (Gordon, 1973: 3-4). The case of emigrant medical doctors and nurses from Nigeria illustrates this problem. Why do Nigerian doctors and nurses depart by the hundreds when any objective observer would agree that health care in Nigeria needs substantial improvement? The answer perhaps is that there are not enough positions in Nigeria with sufficiently high incomes to bid trained medical practitioners away from the incomes they can command abroad. However, the resources devoted to their training, convey little or no positive benefit to Nigeria after their departure. Also, excess qualified manpower tends to draw wasteful investment from the domestic economy in the form of costs that may bear little return. This in turn leads to arbitrary substitution of qualified people by people who are over qualified which indeed is one reason why additional education tends to be socially wasteful although personally profitable. These problems are certainly counter-productive. Such imbalance can decrease the prevailing level of output.

Interestingly, the capital-output ratio is inversely related to both labour and capital productivity. The explanation for this is simply the high labour intensity of Nigeria's production processes. The signs for capacity utilization coefficients in Table 1 are of particular interest. A positive sign for the estimated coefficient shows that an increase in the value of the variable will result in an increase in the level of productivity.

For the overall significance of the model, an analysis of variance needs to be applied (Gujarati, 1995). An analysis of variance uses the F-test, which is similar to the t-test, by formulation of null and alternative hypotheses then comparing F-calculated against F-critical. From the results, it can be concluded that the overall model is highly statistically significant, because F-calculated is greater than F-critical. Finally, the average R-squared is well above 90 per cent, implying that a very high percentage of variation in the dependent variable is explained by the independent variables.

The translog production function specified in this study with its flexible assumptions with respect to technical progress, elasticity of substitution, and returns to scale, yields estimates that are statistically significant with regard to productivity growth. The central findings which emerge from this analysis are discussed below. 
Table 2 gives results from the estimation of a restricted translog specification. The results from the translog model show that capital is positively related to national output while labour maintains its negative impacts across the three specifications.

Table 2 Restricted translog specification of production function in Nigeria, 1970-2000

\begin{tabular}{|l|c|c|c||}
\hline \multicolumn{1}{|c|}{$\begin{array}{c}\text { Independent } \\
\text { variables }\end{array}$} & GDP & LogGDP(t) & LogGDP \\
\hline Lab & -2874.195 & -0.193628 & -0.142196 \\
& $(-0.16)$ & $(0.17)$ & $(-0.81)$ \\
\hline GFCF & 47.56 & 0.003906 & $0.001055^{*}$ \\
& $(0.53)$ & $(0.62)$ & $(1.04)$ \\
\hline LogLab & $-9421554^{* *}$ & $-665.5699^{* *}$ & $-115.124^{* * *}$ \\
& $(-2.27)$ & $(-2.12)$ & $(-3.24)$ \\
\hline LogGFCF & $-483376^{*}$ & $-33.74636^{*}$ & $-5.961559^{* *}$ \\
& $(-1.58)$ & $(-1.50)$ & $(-2.23)$ \\
\hline TFP & $58140.49^{* *}$ & $4.090812^{* *}$ & $0.743410^{* * *}$ \\
& $(2.34)$ & $(2.19)$ & $(3.61)$ \\
\hline Time & 25125.97 & $6.653338^{* *}$ & - \\
& $(0.69)$ & $(2.47)$ & \\
\hline (LogLab) ${ }^{2}$ & $2410180^{* *}$ & $166.1378^{*}$ & $28.6991^{* *}$ \\
& $(2.088)$ & $(1.94)$ & $(2.33)$ \\
\hline (LogGFCF) ${ }^{2}$ & -29679.93 & $-3.756732^{*}$ & -0.436447 \\
& $(-0.89)$ & $(-1.69)$ & $(-1.11)$ \\
\hline (LogLab)(LogGFCF) & -185755.8 & -6.998283 & -2.291801 \\
& $(-0.99)$ & $(-0.56)$ & $(-1.05)$ \\
\hline LogLab(t) & $31002954^{* *}$ & $2180.786^{* *}$ & $396.6552^{* * *}$ \\
& $(2.34)$ & $(2.19)$ & $(3.61)$ \\
\hline LogGFCF(t) & $3214641^{* *}$ & $226.4282^{* *}$ & $41.09030^{* * *}$ \\
& $(2.34)$ & $(2.19)$ & $(3.61)$ \\
\hline AR(1) & - & 0.272090 & - \\
& & $(1.13)$ & \\
\hline $\mathrm{R}^{2}$ & 0.93 & 0.92 & 0.93 \\
\hline Adj. R ${ }^{2}$ & 0.90 & 0.89 & 0.92 \\
\hline DW & 1.79 & 1.86 & 1.87 \\
\hline RSS & $6.00 \mathrm{E}+08$ & 2.19 & 0.06 \\
\hline No. of Observations & 31 & 30 & 30 \\
\hline \hline
\end{tabular}

Note: (a) figures in parentheses are t-values;

(b) $*, * *$, and $* * *$ indicate increasing levels of significance at 10, 5, and 1 percent respectively

Source: Author's calculations 
The results for the translog model show that some of the input parameters are not significant even at 10 per cent level. A pertinent research issue at this juncture is - what do the results indicate for production efficiency and the determinants of inefficiency? The specifications indicate that TFP should be included in the production model because observations are all positive and significant either at 5 per cent or lesser level. However, the TFP parameter in Table 2 may be interpreted loosely in the present context as a symbol of the amount of unexplained variation in technical efficiency. There has been negligible and insignificant growth in total factor productivity between 19702000. It is worth noting that the semi-log trend analysis using the growth accounting framework of TFP growth had shown better results.

Generally, the estimates of the Translog production function suggest the absence of constant returns to scale, and negligible growth in total factor productivity. The results obtained here, like those of Ahluwalia (1991), show that the estimate of TPPG is negative and statistically significant, although increasing returns to scale compensate for the declining efficiency in factor use to a certain extent. Attempts were also made to estimate the commonly used Cobb-Douglas production function, but this empirical exercise was severely hampered by the high noise element in the data, and a strong time trend in technological bias of the production function.

\section{IMPLICATIONS}

Policy and regulatory frameworks should encourage technological upgrading and allow firms to respond to the changing global economy in an efficient way. In order for this to happen, government action is required to get institutions and networks started that can tap information about technology and market trends both locally and worldwide. Adaptation of new technologies to local problems and condition is required for better diffusion, adoption, and use of new technologies.

The process of diffusion and implementation is greatly strengthened if there is feedback from the users of technology to the generators of knowledge through a network of research laboratories linked to the private sector. There is a need, therefore, to pool scientific, technological, and educational resources among different sectors of the economy in order to generate a critical mass of resources beyond individual sector capacities. Workers need an educational and training system, that enables them to increase their experience in dealing with emergent situations and provides them with opportunities for paramount learning. New knowledge must be grounded in what is already understood by knowledge technological concepts and linked to local culture and knowledge. 


\section{CONCLUDING REMARKS}

Most attempts made in the past to estimate production functions for Nigeria have been based on the Cobb-Douglas specification of the production function, which assumes unitary elasticity of substitution between labour and capital and Hicks-neutrality of technical progress. Estimates of production functions for the whole economy using the Translog production function have not been attempted thus far.

In this study, the evidence supporting the effect of technology diffusion on productivity growth through capital goods is examined. An empirical model in which capital productivity is related to the number of technological factors (inputs) employed, is developed. Three conclusions emerge from the analysis. First, there is evidence that technology influences the total variation in Nigeria's productivity growth rates. These results suggest that a large impact on productivity comes from labour than from capital. It is likely that the contribution of capital sources of technology is larger than that of labour in Nigeria.

To confirm this conjecture, high-quality industry-level measures of productivity and technological effort, which are often difficult to obtain, are required. Given the spillover effect of technological advances for a typical developing country such as Nigeria, one would expect a stronger effect on productivity growth resulting from capital inputs, than was estimated here. It also follows that the source of technology diffusion is of significant importance.

Achieving sustainability in development demands new knowledge, which science and technology must provide. Research and innovation are essential for increasing Nigeria's ability to deal with the sustainable development challenge. Technology diffusion and its causes need to be better understood. Its impact, magnitude, tie scale and probability need to be assessed. Trends in technology diffusion and the effects of certain specific actions need to be ascertained. Test solutions must be developed, outcomes predicted and potentially harmful actions mitigated so that informed policy decisions can be made. The pursuit of technical knowledge is an ongoing process and the knowledge base must be constantly renewed and replenished. Experts in the biological, physical and engineering sciences must work closely with experts in the social and behavioural sciences to speed up the application of innovations and insights to the needs of society. There is every confidence that advances in science and technology would enable countries to increase the efficiency of resource use which would in turn raise living standards to levels necessary for global prosperity and long-term sustainability. 
However, technology is not a package that can be bought off the shelf and become immediately productive. Rather it is a commutative process of learning. Thus, for developed and developing countries alike, the ability to realize knowledge-based productivity depends on a country's capacity to tap the global system of generation and transmission of knowledge, generate indigenous knowledge, diffuse and transfer information, and use that knowledge in production processes.

\section{ENDNOTES}

1 The correlation matrices have not been presented here in order to save space. In order to check for multicollinearity, the rule is that, if the simple correlation coefficient of two independent variables is greater than the value of multiple " $R$ ", then one of the two correlation variables has to be dropped (Klein, 1962: 64). 


\section{APPENDIX}

Gross Domestic Product, Inflation Rate, Labour Force, Consumer Price Index, Real Wage \& Unemployment Rate in Nigeria, 1970-2000

\begin{tabular}{|c|c|c|c|c|c|c|c|c|c|}
\hline Year & GDP & INFR & LABF & CPI & $\mathbf{C U}$ & RWAG & UNPR & GDP/LAB & $\begin{array}{l}\text { INFR/ } \\
\text { UNPR }\end{array}$ \\
\hline 1970 & 54148.9 & 13.8 & 32.1 & 10.8 & 74 & 2.5 & 10 & 1686.882 & 23.8 \\
\hline 1971 & 65707 & 15.6 & 32.9 & 12.5 & 74 & 2.6 & 10.5 & 1997.173 & 26.1 \\
\hline 1972 & 69310.6 & 3.2 & 33.8 & 12.9 & 70 & 2.7 & 10.5 & 2050.61 & 13.7 \\
\hline 1973 & 73763.1 & 5.4 & 25.8 & 13.6 & 70 & 2.89 & 9 & 2859.035 & 14.4 \\
\hline 1974 & 82424.8 & 13.4 & 26.6 & 15.4 & 76.6 & 4.03 & 8 & 3098.677 & 21.4 \\
\hline 1975 & 79988.5 & 33.9 & 27.4 & 20.7 & 77.4 & 5.73 & 8 & 2919.289 & 41.9 \\
\hline 1976 & 88854.3 & 21.2 & 28.3 & 25.6 & 78.7 & 6.83 & 8.5 & 3139.728 & 29.7 \\
\hline 1977 & 96098.5 & 15.4 & 29.2 & 29.6 & 72.9 & 8.34 & 8.8 & 3291.045 & 24.2 \\
\hline 1978 & 89020.9 & 16.6 & 30.1 & 34.5 & 71.5 & 10.06 & 8.9 & 2957.505 & 25.5 \\
\hline 1979 & 91190.7 & 11.8 & 31.1 & 38.5 & 70.1 & 10.27 & 9 & 2932.177 & 20.8 \\
\hline 1980 & 96186.6 & 9.9 & 32.1 & 42.3 & 73.3 & 11.88 & 9 & 2996.467 & 18.9 \\
\hline 1981 & 70395.9 & 20.9 & 32.9 & 51.2 & 63.6 & 16.22 & 9 & 2139.693 & 29.9 \\
\hline 1982 & 70157 & 7.7 & 33.8 & 55.1 & 49.7 & 16.5 & 10 & 2075.651 & 17.7 \\
\hline 1983 & 66389.5 & 23.2 & 34.7 & 67.9 & 43 & 16.41 & 11 & 1913.242 & 34.2 \\
\hline 1984 & 63006.4 & 39.6 & 35.6 & 94.8 & 38.3 & 14.66 & 12.5 & 1769.843 & 52.1 \\
\hline 1985 & 68916.3 & 5.5 & 36.6 & 100 & 38.8 & 15.23 & 13 & 1882.959 & 18.5 \\
\hline 1986 & 71075.9 & 5.4 & 37.6 & 105.4 & 40.4 & 14.68 & 13.5 & 1890.317 & 18.9 \\
\hline 1987 & 70741.4 & 10.2 & 38.6 & 116.1 & 42.4 & 16.77 & 15 & 1832.679 & 25.2 \\
\hline 1988 & 77752.5 & 38.3 & 39.7 & 181.2 & 43.8 & 19.89 & 15.6 & 1958.502 & 53.9 \\
\hline 1989 & 83495.2 & 40.9 & 47.7 & 272.7 & 40.3 & 22.82 & 18 & 1750.424 & 58.9 \\
\hline 1990 & 90342.1 & 7.5 & 41.9 & 293.2 & 42 & 26 & 25 & 2156.136 & 32.5 \\
\hline 1991 & 94614.1 & 13 & 43.1 & 330.9 & 38.1 & 29 & 26 & 2195.223 & 39 \\
\hline 1992 & 97431.1 & 44.5 & 44.3 & 478.4 & 37.2 & 25.58 & 27 & 2199.348 & 71.5 \\
\hline 1993 & 100015 & 57.2 & 45.6 & 751.9 & 30.4 & 27.18 & 28 & 2193.316 & 85.2 \\
\hline 1994 & 101330 & 57 & 46.1 & 1180.7 & 39.3 & 26.62 & 28.5 & 2198.048 & 85.5 \\
\hline 1995 & 103503 & 72.8 & 46.8 & 2040.4 & 32.5 & 24.9 & 39.8 & 2211.600 & 112.6 \\
\hline 1996 & 107020 & 29.3 & 47 & 2601.1 & 30.4 & 26.4 & 40.7 & 2277.021 & 70 \\
\hline 1997 & 110400 & 8.5 & 47.4 & 2856 & 30.1 & 27 & 41.6 & 2329.114 & 50.1 \\
\hline 1998 & 113000 & 10 & 52 & 3039 & 31.4 & 27.9 & 42.5 & 2173.077 & 52.5 \\
\hline 1999 & 116400 & 6.6 & 57.9 & 2947.5 & 30 & 30.1 & 43.4 & 2010.363 & 50 \\
\hline 2000 & 120090 & 6.9 & 61.3 & 2993.3 & 32.3 & 33.2 & 44.3 & 1959.054 & 51.2 \\
\hline
\end{tabular}

Source: CBN Statistical Bulletin and Annual Report and Statement of Accounts (various issues) 


\section{REFERENCES}

1 ADIELE, C.J. (2002) Technology, Development and Productivity, Prince Media Group: Atlanta.

2 AHLUWALIA, I.J. (1991) Productivity and Growth in Indian Manufacturing, Oxford University Press: New York.

3 ANTLE, M.J. \& CAPALBO, S.M. (1988) "An introduction to recent developments in production theory and productivity measurement", in Capalbo S.M. and Antle, M.J. Agricultural Productivity: Measurement and Explanation, Resources for the Future Inc.: Washington DC.

4 BERNDT, E.R. \& CHRISTENSEN, L.R. (1973) "The translog function and the substitution of equipment, structures, and labour in U.S. manufacturing: 1929-1968", Journal of Econometrics, 1(1): 81-114.

5 CHRISTENSEN, L. R., JORGENSON, D.W. \& LAM, L.J. (1971) "Conjugate duality and the transcendental logarithmic production function", Econometrica, 39(4).

6 (1973) "Transcendental logarithmic production frontiers", Review of Economics and Statistics, February.

7 COE, D. \& HELPMAN, E. (1995) "International research and development spillovers, "European Economic Review, 39(5).

8 DJANKOV, S. \& HOEKMAN, B. (2000) "Foreign Investment and productivity growth in Czech Enterprises", The World Bank Economic Review, 14(1).

9 EATWELL, J.M. \& NEWMAN, P. (1991) The New Palgrave: A Dictionary of Economics, MacMillan: Tokyo.

10 GORDON, L. E. (1973) "Economic planning and technological change in less developed countries", Economic Development Report, No. 233, Centre for International Affairs, Harvard University, Cambridge: Massachusetts.

11 GUJARATI, N.D. (1995) Basic Econometrics, (int. ed.) McGraw-Hill: New York.

12 IYANIWURA, O. \& OSOBA, A.M. (1983) "Measuring productivity; conceptual and statistical problems: Improvement of statistics" in Osoba A.M. (ed.) Productivity in Nigeria, Ibadan: Proceedings of a National Conference, NISER.

13 KLEIN, L.R. (1962) An Introduction to Econometrics, Prentice-Hall Inc.: New Jersey.

14 LUCAS, R. (1988) "On the mechanics of economic development", Journal of Monetary Economics, 22(1).

15 NAVARETTI, G.B. \& TARR, D.G. (2000) "International knowledge flows and economic performance: A review of evidence", The World Bank Economic Review, 1(14). 
16 NDIYO, N.A. (2002) "The paradox of education expenditure and economic growth in Nigeria: An empirical evidence", Nigerian Economic Society Conference Proceedings, August.

17 NELSON, R.R. (1973) "Recent exercise in growth accounting: new understanding or dead end?" American Economic Review, 63, June.

18 OLAOYE, A.O. (1985) "Total factor productivity trends in Nigerian manufacturing", Nigerian Journal of Economic and Social Studies, 27(3): 317-45.

19 OYERANTI, G. (2000) "Concept and measurement of productivity", Abeokuta: CBN $9^{\text {th }}$ Annual Conference Proceedings, June 12-16.

20 PROKOPENKO, J. (1987) Productivity Management: A Practical Handbook, International Labour Organisation: Geneva.

21 ROMA, P. (1990) "Endogenous technological change", Journal of Political Economy, 98(5).

22 SAMUELSON, P.A. \& NORDHAUS, W.D. (1995) Economics, (15th ed.) McGraw-Hill, New York.

23 SOLOW, R.M. (1957) "Technical change and the aggregate production function", The Review of Economics and Statistics, August (39): 312-20.

24 STOKEY, N. (1988) "Learning-by-doing and the introduction of new goods", Journal of Political Economy, 96(4). (1991) "Human capital, product quality and growth", Quarterly Journal of Economics, 1: 6-9.

26 YOUNG, A. (1991) "Learning-by-doing and the dynamic effects of international trade", Quarterly Journal of Economics, 106(2). 